\title{
Effect of HIV and Antiretroviral Treatment on Auditory Functions
}

\author{
Ravinder S. Minhas ${ }^{1}$ Dhanashree A. Iyengar ${ }^{1} \quad$ Jagdeep S. Thakur ${ }^{1}$ Ramesh K. Azad $^{1}$ \\ ${ }^{1}$ Department of ENT, Indira Gandhi Medical College (IGMC), \\ Shimla, HP, India \\ Int Arch Otorhinolaryngol 2018;22:378-381.

\begin{abstract}
Address for correspondence Jagdeep S. Thakur, MBBS, MS Circular Road, Lakkar Bazar, Shimla, HP, 171001, India
\end{abstract} \\ Department of ENT, Indira Gandhi Medical College (IGMC), \\ (e-mail: anujagdeep@yahoo.co.in).
}

\begin{abstract}
Introduction Numerous studies have evaluated auditory functions in human immunodeficiency virus (HIV) patients; however, these studies had a few major limitations in terms of methodology as they used mainly evoked audiometry although this method is expensive, time consuming and not widely available. Therefore, we conducted a study in naïve HIV subjects with routine audiometry.

Objective To determine the effect of HIV and of the drugs used to treat it on the auditory functions.

Methods A prospective observational study was conducted in a medical college with 25 naive HIV-seropositive patients for over a year. Pure tone audiometry $(250-8,000$ $\mathrm{Hz}$ ) and CD4 T-lymphocyte count were performed at the time of enrollment and 6 months after commencement of highly active antiretroviral treatment.

Results The subjects had increased hearing thresholds at high frequencies ( $4 \mathrm{KHz}$ and $8 \mathrm{KHz})$ in both ears at the time of enrollment that persisted at the same level $(p>0.05)$ on follow-up at 6 months. None of the subjects had any other otological symptom during the 6 months of observation. Seven subjects had sensorineural hearing loss in one or both ears at 0 and 6 months. These observations did not show any significant difference on Wilcoxon-signed-rank test. Spearman correlation did not find a significant

Keywords

- HIV

- hearing loss

- audiometry

- CD4 T-lymphocyte count correlation ( $p>0.05$ ) between CD4 T-lymphocyte counts and pure tone audiometry during the study.

Conclusion We found high-frequency hearing loss in all subjects with no relation with highly active antiretroviral therapy (HAART) and severity of the disease. This study advocates hearing assessment with pure tone audiometry in HIV subjects so that intervention can be initiated in a timely manner.
\end{abstract}

\section{Introduction}

The human immunodeficiency virus (HIV), being neurotropic and lymphotropic, may affect the neuraxis at any level. The virus infects T-helper cells via CD4 T-cell receptors, causing functional impairment of the T-cells and their depletion.

Hearing impairment has been documented as one of the manifestations in HIV-seropositive individuals. While reducing morbidity and secondary manifestations are the main

received

November 11, 2017

accepted

February 19, 2018

published online

March 29, 2018

$10.1055 / \mathrm{s}-0038-1639594$. ISSN $1809-9777$. objectives of antiretroviral treatment these days, hearing loss has been overlooked. Although HIV-seropositive patients with otitis media usually visit or are referred to an ENT clinic, asymptomatic or mild hearing loss due to other causes remains ignored or undetected. Otitis media can lead to conductive hearing loss in these patients, whereas sensorineural hearing loss has been attributed to ototoxicity of antiretroviral drugs or a direct effect of HIV on the central nervous system, peripheral nerves, and cochleo-vestibular apparatus. ${ }^{1-5}$ Numerous studies have evaluated the auditory

Copyright @ 2018 by Thieme Revinter

Publicações Ltda, Rio de Janeiro, Brazil

License terms

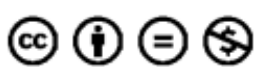


functions in HIV patients and found hearing loss associated with progression of the disease. ${ }^{6,7}$ However, these studies have two major limitations: i) they included subjects with ear symptoms or previous systemic disease/treatment, which obviously required hearing evaluation in general; ii) few of these studies performed evoked response audiometry, which is not a routine clinical practice. Moreover, evoked response audiometry is an extremely inefficient method of determining hearing thresholds and less precise than behavioral pure tone audiometry (PTA). When possible (for example, with adults and older children), behavioral audiometry is always the preferred method of hearing assessment because it is faster, easier, cheaper, more precise, and widely available. Therefore, we conducted a prospective, observational study in naïve HIV subjects (those who have not yet started antiretroviral treatment and on whom audiometry of any kind has not been performed before enrollment) with routine audiometry to find the effect of HIV and antiretroviral treatment on auditory functions, so that any hearing impairment in these patients can be detected even in a general ENT clinic and appropriate interventions can be initiated timely to improve the quality of life.

\section{Methods}

After institutional ethical board approval, 25 naïve HIVseropositive subjects ( 16 female and 9 male) with a mean age of $37.64 \pm 6.55$ years were enrolled after adjustment of confounding variables and written informed consent. Subjects with abnormal (healed, thin, retracted, bulging, perforated) tympanic membrane, tinnitus, vertigo, history of systemic disease, opportunistic infection or treatment for it, diseases or any other known causes of hearing loss and conductive hearing loss on PTA were excluded. All subjects were placed in the same environmental conditions during the study period, and any exposure to noise, otitis media, or ototoxic drugs needed to be disclosed and would preclude the subject from participating in the study.

The subjects underwent detailed history, clinical, audiological, hematological and biochemical evaluation at the time of enrollment and after 6 months of highly active antiretroviral therapy (HAART: Efavirenz, Lamivudine, and Tenofovir Dis- oproxil Fumarate). The subjects were evaluated for complete blood count, $\mathrm{CD} 4$ counts, lipid profile, liver, and renal functions to exclude metabolic or endocrine disorders. The PTA was performed in a certified sound-treated room with the clinical audiometer AC 40 (Interacoustics A/S, Assens, Denmark) between $250-8,000 \mathrm{~Hz}$ for air conduction using circumaural headphones and up to $4,000 \mathrm{~Hz}$ for bone conduction. This audiometer, calibrated annually, had been calibrated 8 months before the first enrollment in the study. Subjects with conductive hearing loss were excluded from the study as we believed that the disease, or the medication used to treat it, could affect the outcome of our study. Subjects showing sensorineural hearing loss on speech frequencies were then evaluated for tone decay test (TDT) using the Olsen and Noffsinger method and short increment sensitivity index (SISI) in similar test conditions. The SISI test was performed using the Jerger method, which involves presentation of $20 \mathrm{~dB}$ suprathreshold tone in the range of $1,000-4,000 \mathrm{~Hz}$ frequencies. The ear being tested was delivered a $5 \mathrm{~dB}$ increment in the tone every 5 seconds, and the test was repeated until the subject could identify the change in loudness. After identification, the tone increment was reduced sequentially. Then finally, the ear was delivered a $1 \mathrm{~dB}$ increment in the tone every 5 seconds for 20 times. The result is denoted as a percentage of the number of correct responses out of 20 . Observations were analyzed using non-parametric tests (Wilcoxon signed-rank test and Spearman rank correlation coefficient).

\section{Observation and Results}

At the time of enrollment of the subjects, their mean hearing thresholds for speech frequencies ( $500 \mathrm{~Hz}, 1 \mathrm{KHZ}$ and $2 \mathrm{KHZ}$ ) were $24.6 \pm 16.8 \mathrm{~dB}$ and $24.06 \pm 16.8 \mathrm{~dB}$ in the right and the left ear, respectively. These thresholds remained almost at the same levels $(p>0.05)$ on re-evaluation after 6 months $(24.46 \pm 16.8 \mathrm{~dB}$ and $24.06 \pm 16.45 \mathrm{~dB}$ in the right and the left ear, respectively). However, all subjects had increased hearing thresholds at high frequencies $(4 \mathrm{KHz}$ and $8 \mathrm{KHz}$ ) in both ears at the time of enrollment that persisted at the same level $(p>0.05)$ at the follow-up after 6 months (-Table $\mathbf{1}$ ). None of the subjects displayed any other otological symptoms during the observation period of 6 months.

Table 1 Hearing thresholds and Wilcoxon Signed-rank Test results

\begin{tabular}{|c|c|c|c|c|c|c|}
\hline \multirow{3}{*}{$\begin{array}{l}\text { Frequency } \\
(\text { In Hz) }\end{array}$} & \multicolumn{6}{|c|}{ Hearing Thresholds (Mean \pm SD in $\mathrm{dB}$ ) and statistical significance } \\
\hline & \multicolumn{3}{|l|}{ Right ear } & \multicolumn{3}{|l|}{ Left ear } \\
\hline & At 0 months & At 6 months & $\begin{array}{l}P \text {-value } \\
\text { (2-tailed) }\end{array}$ & At 0 months & At 6 months & $\begin{array}{l}P \text {-value } \\
\text { (2-tailed) }\end{array}$ \\
\hline 250 & $23.2 \pm 15.19$ & $23.2 \pm 15.8$ & 1.000 & $23.2 \pm 17.31$ & $23.6 \pm 16.68$ & 0.527 \\
\hline 500 & $22.2 \pm 16.39$ & $23.8 \pm 16.79$ & 0.074 & $24.4 \pm 17.99$ & $24.4 \pm 17.75$ & 1.000 \\
\hline 1,000 & $25.6 \pm 18.56$ & $25.2 \pm 17.94$ & 0.669 & $24.4 \pm 18.1$ & $23.2 \pm 15.54$ & 0.242 \\
\hline 2,000 & $26 \pm 16.39$ & $24.4 \pm 16.54$ & 0.059 & $23.4 \pm 15.39$ & $24.6 \pm 16.89$ & 0.279 \\
\hline 4,000 & $30.6 \pm 15.23$ & $30.2 \pm 16.23$ & 0.717 & $29.6 \pm 15.47$ & $29.6 \pm 15.47$ & 0.980 \\
\hline 8,000 & $35 \pm 18.37$ & $34.8 \pm 18.62$ & 0.837 & $32 \pm 16.39$ & $32 \pm 16.46$ & 0.850 \\
\hline
\end{tabular}


Seven subjects had sensorineural hearing loss in one or both ears with hearing thresholds of $49.99 \pm 24.92 \mathrm{~dB}$ (range 26.66-90 dB) and $50.33 \pm 23.78 \mathrm{~dB}$ (range 30$88.33 \mathrm{~dB}$ ) in the right ear at 0 and 6 months, respectively, while the thresholds in the left ear were $46.38 \pm 23.00 \mathrm{~dB}$ (range $30-88.33 \mathrm{~dB}$ ) and $45.83 \pm 22.18 \mathrm{~dB}$ (range 30-85 dB) for the same periods of time. These observations did not show any significant difference on the Wilcoxon signed-rank test. These seven patients were further subjected to the SISI and TDT tests to determine the type of sensorineural loss. They did not show tone decay at 0 or 6 months after TDT, while the SISI (mean \pm SD) results were $79.29 \pm 5.35 \%$ and $81.43 \pm 2.44 \%$ at 0 and 6 months, respectively, indicating sensory (cochlear) hearing loss.

The mean CD4 T-lymphocyte counts were $347.08 \pm 245.9$ cells $/ \mu \mathrm{L}$ and $370.6 \pm 203.13$ cells $/ \mu \mathrm{L}$ at 0 and 6 months, respectively, that had no significance on the Wilcoxon signed-rank test $(p>0.05)$. The Spearman correlation coefficient did not find a significant correlation $(p>0.05)$ between CD4 T-lymphocyte counts and PTA during the study ( - Tables $\mathbf{2}$ and $\mathbf{3}$ ).

One subject had a marked decrease in her CD4 count (538 cells $/ \mu \mathrm{L}$ to 82 cells $/ \mu \mathrm{L}$ ) at follow-up but her hearing threshold remained normal for each frequency. For the subjects with hearing loss at speech frequencies $500 \mathrm{HZ}, 1 \mathrm{KHz}$ and $2 \mathrm{KHz}$, the mean CD4 T-lymphocyte count was 341.2 cells $/ \mu \mathrm{L}$ in five patients with mild sensorineural hearing loss, 29 cells $/ \mu \mathrm{L}$ in a patient with moderate-severe sensorineural hearing loss, and 26 cells/ $\mu \mathrm{L}$ in a patient with severe hearing loss that

Table 2 Spearman correlation between hearing thresholds and CD4 at the time of enrollment

\begin{tabular}{|l|l|l|l|l|}
\hline \multirow{2}{*}{$\begin{array}{l}\text { Frequency } \\
\text { (in Hz) }\end{array}$} & \multicolumn{2}{|l|}{ Right ear } & Left Ear \\
\cline { 2 - 5 } & $\begin{array}{l}\text { Correlation } \\
\text { Coefficient }\end{array}$ & $\begin{array}{l}\text { P-value } \\
\text { (2-tailed) }\end{array}$ & $\begin{array}{l}\text { Correlation } \\
\text { Coefficient }\end{array}$ & $\begin{array}{l}\text { P-value } \\
\text { (2-tailed) }\end{array}$ \\
\hline 250 & -0.005 & 0.982 & 0.045 & 0.830 \\
\hline 500 & 0.011 & 0.960 & -0.012 & 0.954 \\
\hline 1000 & 0.010 & 0.961 & 0.028 & 0.894 \\
\hline 2000 & -0.120 & 0.567 & 0.043 & 0.838 \\
\hline 4000 & -0.294 & 0.154 & -0.142 & 0.499 \\
\hline 8000 & -0.389 & 0.055 & -0.139 & 0.507 \\
\hline
\end{tabular}

Table 3 Spearman correlation between hearing thresholds and CD4 at 6 months

\begin{tabular}{|l|l|l|l|l|}
\hline \multirow{2}{*}{$\begin{array}{l}\text { Frequency } \\
\text { (in Hz) }\end{array}$} & \multicolumn{3}{|l|}{ Right ear } & Left Ear \\
\cline { 2 - 5 } & $\begin{array}{l}\text { Correlation } \\
\text { Coefficient }\end{array}$ & $\begin{array}{l}\text { P-value } \\
\text { (2-tailed) }\end{array}$ & $\begin{array}{l}\text { Correlation } \\
\text { Coefficient }\end{array}$ & $\begin{array}{l}\text { P-value } \\
\text { (2-tailed) }\end{array}$ \\
\hline 250 & 0.076 & 0.717 & 0.087 & 0.679 \\
\hline 500 & 0.247 & 0.234 & -0.062 & 0.767 \\
\hline 1,000 & 0.001 & 0.996 & 0.040 & 0.849 \\
\hline 2,000 & 0.008 & 0.969 & -0.058 & 0.784 \\
\hline 4,000 & -0.194 & 0.354 & -0.004 & 0.984 \\
\hline 8,000 & -0.297 & 0.149 & -0.025 & 0.906 \\
\hline
\end{tabular}

remained so despite improvement in the CD4 count during the follow-up.

\section{Discussion}

The HIV causes profound immunological impairment by invading the cells related to the immune system, which leads to reduction in lymphocytes and to opportunistic infections. The T-helper lymphocyte via CD4 receptor is primarily infected, which leads to its functional impairment and depletion. ${ }^{1}$

The prevalence of hearing impairment in HIV-seropositive patients is $14-49 \% .^{6,8,9}$ This hearing loss can be due to secondary opportunistic infections and ototoxic drugs or can be a direct effect of the virus on the central nervous system, peripheral nerves, vestibulocochlear nerve, or cochlea. Secondary infection leading to otitis media is the most common presentation in HIV patients and can lead to conductive, sensorineural, or mixed hearing loss. However, systemic infections in the form of cytomegalovirus, mumps, measles, Cryptococcus, tuberculosis, or ototoxicity of drugs that are used to treat these infections also contribute prominently in sensorineural hearing loss. 5,10

The direct effect of HIV on the cochlea has been established in a study by Pappas et $\mathrm{al}^{2}{ }^{2}$ who identified extracellular viral-like particles in the tectorial membrane of three HIV positive patients with sensorineural hearing loss. They also identified pathologic changes in the labyrinthine wall, epithelial lining of macula and crista, and inclusion bodies in the supporting cells. Torre et a ${ }^{10}$ performed lowand high-frequency PTA assessment of HIV-positive subjects on HAART and age-matched HIV-negative controls. They found significantly higher hearing thresholds at both low $(250-2,000 \mathrm{~Hz})$ and high frequencies $(3-8 \mathrm{KHz}$ ) among the HIV-seropositive individuals in comparison to the HIVnegative controls. There was no correlation between CD4 T-lymphocyte count and hearing thresholds in HIV seropositive individuals. They concluded that low-frequency hearing loss can impair communication in HIV patients.

We also found increased hearing thresholds at $4-8 \mathrm{KHz}$ in all subjects with no significant changes after 6 months. Seven subjects with sensorineural hearing loss also did not show any significant difference after 6 months. The TDT and SISI tests suggested cochlear pathology in these seven subjects. We also did not find any statistically significant correlation between the overall CD4 counts and sensorineural hearing loss. However, individually, one subject had moderate-severe hearing loss (CD4 count of 29 cells $/ \mu \mathrm{L}$ ) and another had severe sensorineural hearing loss (CD4 count of 26 cells $/ \mu \mathrm{L}$ ). These finding may suggest a relationship between the severity of the sensorineural hearing loss and CD4 T-lymphocyte counts. However, contrary to this assumption, another subject had a marked decrease in CD4 count (from 538 cells $/ \mu \mathrm{L}$ on enrollment to 82 cells $/ \mu \mathrm{L}$ after 6 months) on the follow-up; yet, her hearing thresholds remained normal at each frequency. Palacios et $\mathrm{al}^{11}$ have found abnormal audiologic observations in subjects with prolonged HIV infection, viral load, and low CD4 counts. 
Assuiti et al $^{12}$ have conducted a review and did not find any direct association between hearing loss and antiretroviral drugs. They concluded that hearing loss in HIV-positive/seropositive patients is multifactorial and can be attributed to the direct effect of HIV, opportunistic infection, and ototoxicity due to HAART or drugs used to treat opportunistic infections. We found that hearing impairment had no relation with HAART, duration of treatment, or severity of the disease, indicating that cochlear functions are impaired by HIV either directly or indirectly through premature aging.

This study indicated cochlear damage, which could have been caused due to some unknown etiology (secondary infections or drugs used to treat them) that subjects failed to recall. Evoked response audiometry may be taken as a limitation of this study, but we deliberately excluded the use of evoked response audiometry for evaluation as we wanted to observe changes through PTA, which is quick, inexpensive, and widely available in comparison with evoked response audiometry and can enable even a general ENT clinic to find subtle changes in the hearing thresholds, so that timely and appropriate interventions can be initiated.

\section{Conclusion}

Auditory functions are impaired in HIV infection, but its assessment remains within the research area only. We conducted a study to assess auditory functions in HIV-infected patients with routine PTA and we found hearing loss at high frequencies in all HIV-positive/seropositive subjects. We advocate the use of PTA in all HIV-positive/seropositive patients so that adequate intervention can be initiated as early as possible to avoid morbidity.

\section{References}

1 Hausler R, Vibert D, Koralnik IJ, Hirschel B. Neuro-otological manifestations in different stages of HIV infection. Acta Otolaryngol Suppl 1991;481:515-521

2 Pappas DG Jr, Chandra Sekhar HK, Lim J, Hillman DE. Ultrasructural findings in the cochlea of AIDS cases. Am J Otol 1994;15(04):456-465

3 Bankaitis A, Schountz T. HIV-related ototoxicity. Semin Hear 1998;19(02):155-163

4 Simdon J, Watters D, Bartlett S, Connick E. Ototoxicity associated with use of nucleoside analog reverse transcriptase inhibitors: a report of 3 possible cases and review of the literature. Clin Infect Dis 2001;32(11):1623-1627

5 Schouten JT, Lockhart DW, Rees TS, Collier AC, Marra CM. A prospective study of hearing changes after beginning zidovudine or didanosine in HIV-1 treatment-naïve people. BMC Infect Dis 2006;6:28

6 van der Westhuizen Y, Swanepoel W, Heinze B, Hofmeyr LM. Auditory and otological manifestations in adults with HIV/AIDS. Int J Audiol 2013;52(01):37-43

7 Maro II, Moshi N, Clavier OH, et al. Auditory impairments in HIVinfected individuals in Tanzania. Ear Hear 2014;35(03):306-317

8 Khoza K, Ross E. Auditory function in a group of adults infected with HIV/AIDS in Gauteng, South Africa. S Afr J Commun Disord 2002;49:17-27

9 Sooy CD, Gerberding JL, Kaplan MJ. The risk for otolaryngologists who treat patients with AIDS and AIDS virus infection: report of an in-process study. Laryngoscope 1987;97(04):430-434

10 Torre P III, Zeldow B, Hoffman HJ, et al; Pediatric HIVAIDS Cohort Study. Hearing loss in perinatally HIV-infected and HIV-exposed but uninfected children and adolescents. Pediatr Infect Dis J 2012; 31(08):835-841

11 Palacios GC, Montalvo MS, Fraire MI, Leon E, Alvarez MT, Solorzano F. Audiologic and vestibular findings in a sample of human immunodeficiency virus type-1-infected Mexican children under highly active antiretroviral therapy. Int J Pediatr Otorhinolaryngol 2008;72(11):1671-1681

12 Assuiti LF, Lanzoni GM, Santos FC, Erdmann AL, Meirelles BH. Hearing loss in people with HIV/AIDS and associated factors: an integrative review. Rev Bras Otorrinolaringol (Engl Ed) 2013;79(02):248-255 